\title{
Biochemical Fingerprinting of Methicillin-Resistant Staphylococcus aureus Isolated From Sewage and Hospital in Iran
}

\author{
Fateh Rahimi ${ }^{1}$; Majid Bouzari ${ }^{1, *}$ \\ ${ }^{1}$ Department of Biology, Faculty of Sciences, University of Isfahan, Isfahan, IR Iran \\ *Corresponding author: Majid Bouzari, Department of Biology, Faculty of Sciences, University of Isfahan, IR Iran. Tel:+98-3137932459, Fax: +98-3137932456, E-mail: bouzari@sci.ui.ac.ir
} Received: April 27, 2014; Revised: September 8, 2014; Accepted: November 4, 2014

\begin{abstract}
Background: Methicillin-resistant Staphylococcus aureus (MRSA) is known as a common pathogen in nosocomial and communityacquired infections. Sewage acts as an environmental reservoir and may have a significant role in development and dissemination of antibiotic resistance.

Objectives:This study was undertaken to determine the epidemiological relatedness between the MRSA isolated from sewage and human infections.

Materials and Methods: Samples were collected from a referral hospital and also a sewage treatment plant in Tehran, Iran, during 2010. All the MRSA isolates were identified at the species level and typed using Phene plate (PhP) system and SCCmec typing. Antibiotic susceptibility tests were also performed.

Results: Of the 1142 isolates, 200 MRSA strains from the sewage $(n=100)$ and the clinic $(n=100)$ were isolated.Distinct PhP types, consisting of 16 common types and 13 single types, and also 3 different staphylococcal cassette chromosome mec (SCCmec) types (III, IVa and IVc) were found amongst the MRSA isolated from the two different sources. The results of antibiotic susceptibility testing showed an increased resistance to penicillin, ciprofloxacin, erythromycin, clindamycin and tetracycline. In addition, none of the isolates showed resistance to vancomycin, quinupristin -dalfopristin and linezolid.

Conclusions: The presence of common PhP types and also SCCmec type III, as an indicator for hospital strains, among the isolates, may indicate an epidemiological link between clinical and sewage MRSA isolates in Tehran.
\end{abstract}

Keywords: Methicillin- Resistant Staphylococcus aureus; Sewage; Hospital; Staphylococcal Cassette Chromosome mec; Typing

\section{Background}

Staphylococcus aureus is a common cause of nosocomial and community-acquired infections, ranging from skin infections to necrotizing pneumonia $(1,2)$. Methicillinresistant S. aureus (MRSA) isolates with high-level resistance to beta-lactam antibiotics have been reported to be spread and are epidemic in different hospitals in the world (3). The resistance to methicillin is mediated with mecA and novel mecC genes (3-5). Staphylococcal cassette chromosome mec (SCCmec) is the only vector for the mecA gene and its transfer occurs frequently $(3,4)$. Although hospital-acquired MRSA (HA-MRSA) is one of the most frequent causes of hospital-associated infections, community-acquired MRSA (CA-MRSA) has recently emerged as an additional threat, causing infections in healthy individuals with no healthcare-associated risk factors $(3,6)$. As a large amount of antibiotics prescribed are introduced in the environment in an active form, sewage may act as an environmental reservoir and may have a significant role in the development and dissemination of antibiotic resistance, e.g. beta-lactam antibiotics which are detected in sewage systems and surface waters $(3,7)$. The role of horizontal gene transfer in the spread of antibiotic resistance in the environment has been documented (8).
Ohlsen and colleagues (9) described the transfer of genes encoding antibiotic resistance by $S$. aureus in wastewater in vitro. Detection of the mecA gene has also been reported in hospitals and sewage (10-12). Using cultivation and molecular techniques, the presence of MRSA in municipal wastewater has been reported $(10,11)$. Therefore, sewage treatment plants (STPs) could be a potential source for dissemination and development of MRSA strains.

\section{Objectives}

This study was undertaken to determine the epidemiological relatedness between the MRSA strains isolated from sewage and human infections using a combination of different typing methods.

\section{Materials and Methods}

\subsection{Sewage Sampling}

In 2010, an urban STP located in the west of Tehran was selected for collecting the sewage samples. Three samples were collected in sterile bottles $(250 \mathrm{~mL})$ and transferred to the laboratory in a cold chain. After a five-fold di-

Copyright (C) 2015, Ahvaz Jundishapur University of Medical Sciences. This is an open-access article distributed under the terms of the Creative Commons Attribution-NonCommercial 4.0 International License (http://creativecommons.org/licenses/by-nc/4.0/) which permits copy and redistribute the material just in noncommercial usages, provided the original work is properly cited. 
luting with phosphate buffered saline, the samples were filtered using a $0.45 \mu \mathrm{m}$ membrane (Millipore Corporation, Bedford, MA) and were cultured in Baird Parker agar (Merck KGaA, Darmstadt, Germany) plates by the same procedure described in literature for enterococci (13-15).

\subsection{Clinical Samples}

Specimens ( $n=489$ ) were collected from patients in a referral hospital in Tehran during 2010. Using standard microbiological techniques such as catalase test, oxidase reaction, growth in $10-15 \%$ sodium chloride, mannitol fermentation, DNase and coagulase tests, the isolates were confirmed as S. aureus and were used for isolation of MRSA strains, as described previously (16-18).

\subsection{Antibiotic Susceptibility Tests}

According to the guidelines of Clinical and Laboratory Standards Institute (CLSI) (19), all the S. aureus isolates were examined for susceptibility to oxacillin $(1 \mu \mathrm{g})$, using disc diffusion method. E-test (AB, Biomérieux, Marcy l'Etoile, France) was used to determine the minimum inhibitory concentrations (MICs) for oxacillin and vancomycin of all the collected MRSA isolates, according to the manufacturer's instructions. Sixteen common antibiotics were employed to determine the susceptibility of the MRSA isolates by disc diffusion method, as described by CLSI (19). These included amikacin $(30 \mu \mathrm{g})$, chloramphenicol $(30 \mu \mathrm{g})$, ciprofloxacin $(5 \mu \mathrm{g})$, clindamycin $(2 \mu \mathrm{g})$, erythromycin $(15 \mu \mathrm{g})$, gentamicin $(10 \mu \mathrm{g})$, kanamycin (30 $\mu \mathrm{g})$, linezolid $(30 \mu \mathrm{g})$, minocycline $(30 \mu \mathrm{g})$, nitrofurantoin $(300 \mu \mathrm{g})$, penicillin $(5 \mu \mathrm{g})$, quinupristin-dalfopristin (15 $\mu \mathrm{g})$, rifampicin $(5 \mu \mathrm{g})$, sulfamethoxazole-trimethoprim $(1.25-23.75 \mu \mathrm{g})$, tetracycline $(30 \mu \mathrm{g})$, and tobramycin (10 $\mu \mathrm{g}$ ) (Mast Diagnostics, Merseyside, UK).

\subsection{DNA Extraction and Polymerase Chain Reaction}

High Pure PCR Template Preparation Kit (Roche, Mannheim, Germany) was used to extract the DNA according to the manufacturer's guidelines with some modifications. PCR primers for nucA and mecA genes were prepared according to Du et al. (20). PCR conditions were as described previously (21).

\subsection{Staphylococcal Cassette Chromosome mec and ccr Typing}

A multiplex PCR typing assay was used for typing the SCCmec gene which contained eight pairs of primers including the unique and specific primers for SCCmec types and subtypes I, II, III, IVa, IVb, IVc, IVd, and V (22). Another multiplex PCR was used for characterization of ccr gene complexes which employed four sets of primers specific for each of the $c c r$ genes, i.e. $c c r A B-\beta 2, c c r A B-\alpha 2, c c r A B-\alpha 3$, and $c c r A B-\alpha 4$ (22). The multiplex PCR mixture and the PCR cycles were as previously described by Zhang et al. (22).

\subsection{Detection of pvl Gene}

For detection of $p v l$ gene encoding PVL toxin among MRSA isolates, specific primers were used, as previously described by McClure and colleagues (23). The PCR cycles and mixture were according to McClure et al.(23).

\subsection{Biochemical Fingerprinting}

PhP-RF plates (PhPlate AB, Stockholm, Sweden) were used to type the 200 MRSA isolates. To measure the kinetics of bacterial metabolism of 23 substrates and a control, four sets of dehydrated reagents were used to differentiate the $S$. aureus strains (24). The absorbance values $\left(\mathrm{A}_{620}\right)$ of each microplate wells that were incubated at $37^{\circ} \mathrm{C}$, were measured at 16-, 40-, and 64-hour intervals (15). The diversity of the bacterial populations was calculated as Simpson's index of diversity (Di) $(15,25)$. PhPWin software (PhPlate Microplates Techniques AB, Sweden) was used for optical readings, calculation of correlation coefficients, diversity indexes, and clustering (15).

\section{Results}

\subsection{Prevalence of Methicillin-Resistant Staphylo- coccus aureus Isolates}

Totally, 653 S. aureus strains were isolated from the sewage samples. One hundred (15.3\%) MRSA strains were isolated from this STP. Of the total 489 clinical isolates, 100 (20.4\%) strains were determined as MRSA. The frequencies of positive cases in clinical samples were as follows: 207 (42\%) from wound, 96 (20\%) urine, 69 (14\%) sputum, 39 ( $8 \%$ ) blood, 27 (6\%)CSF, 26 (5\%) nose, and 25 (5\%) abscess.

\subsection{Antibiotic Susceptibility Testing}

The percentages of antimicrobial resistance of the MRSA strains isolated from different sources are shown in Figure 1. High resistance to ciprofloxacin (91\%), erythromycin (90\%), tobramycin (89\%), kanamycin (88\%), clindamycin $(84 \%)$ and tetracycline $(81 \%)$ was observed in clinical cases. In contrast, low resistance to nitrofurantoin (3\%) was detected. Furthermore, no resistance to vancomycin, synercid and linezolid was observed in clinical isolates. Concomitant resistance to $\mathrm{Cip} / \mathrm{E} / \mathrm{Tn} / \mathrm{K} / \mathrm{CD} / \mathrm{T}$ was found in about $80 \%$ of the human MRSA isolates. This rate was somehow more for sewage isolates (Figure 1).

Susceptibility to all the antibiotics tested except for penicillin was observed in $7 \%$ and $6 \%$ of clinical and sewage isolates, respectively. Moreover, $18 \%$ and $13 \%$ of clinical and sewage isolates, respectively, showed resistance to all the different antibiotics except for vancomycin, synercid, nitrofurantoin, linezolid and chloramphenicol. The oxacillin MIC for all the MRSA isolated from humans and sewage showed that all the isolates were resistant to oxacillin (MIC $\geq 4 \mu \mathrm{g} / \mathrm{mL}$ ). Moreover, $49 \%$ of clinical isolates and $58 \%$ of sewage isolates showed high-level resistance 
Figure 1. The Resistance Rate of Methicillin-Resistant Staphylococcus aureus Strains Isolated From Clinical and Sewage Samples Against the 14 Antibiotics Tested

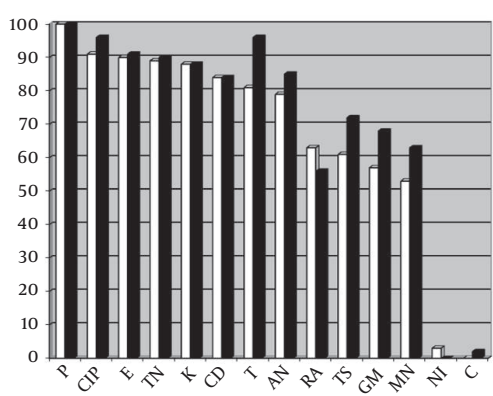

Abbreviations: AN, amikacin; C, chloramphenicol; CD, clindamycin; CIP, ciprofloxacin; E, erythromycin; GM, gentamicin; K, kanamycin; MN, minocycline; NI, nitrofurantoin; P, penicillin; RA, rifampicin; T, tetracycline; TN, tobramycin; TS, cotrimoxazole.
(MIC $\geq 256 \mu \mathrm{g} / \mathrm{mL}$ ) to oxacillin. In addition, $7 \%$ of clinical isolates and $6 \%$ of sewage isolates showed low resistance to oxacillin (MIC $=4 \mu \mathrm{g} / \mathrm{mL})$.

\subsection{Biochemical Fingerprinting}

Diverse (diversity index, Di = 0.975) PhP types were detected among the MRSA strains isolated from clinical and sewage sources. The 200 isolates were discriminated into 29 types with 13 single types (6.5\%) and 16 common types (CTs) (93.5\%) (Figure 2). Each (C-BPT) (common biochemical phenotypes) included 2-98 strains. The highest number of MRSA strains was categorized in CT11 (98 isolates, 49\%) and was considered as the dominant common type. In general, isolates in the same PhP type showed different antibiotic resistance patterns, indicating no relatedness between their clonal dissemination and also their antibiotic resistance patterns (i.e. ST2, ST3).

Figure 2. An Unweighted Pair Group With Arithmetic Averages Dendrogram, Showing the Methicillin-Resistant Staphylococcus aureus Strains Isolated From Different Sewage Treatment Plants and Clinical Samples in Tehran During 2010
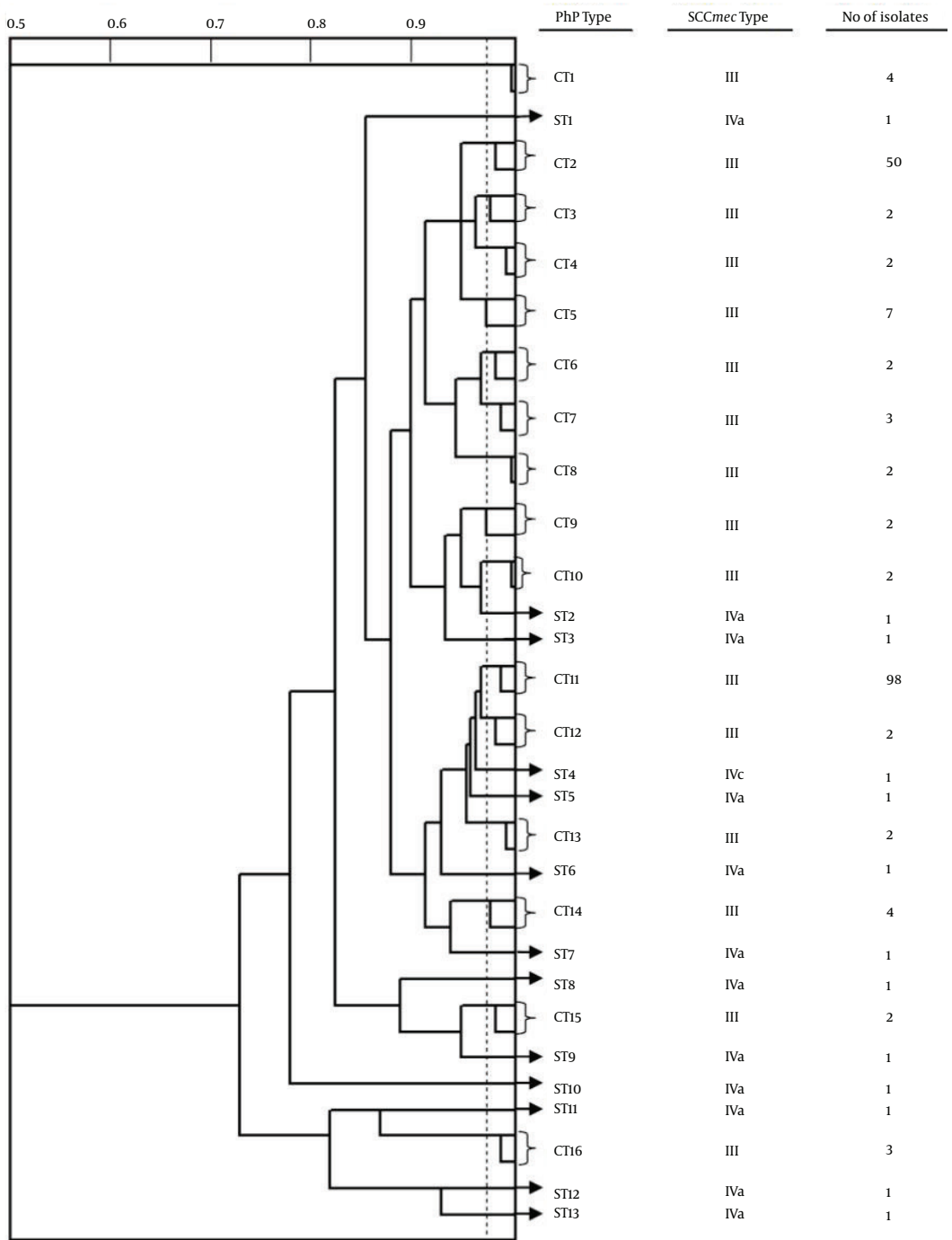

In this dendrogram, only two isolates of each CT have been included. 
Rahimi F et al.

\subsection{Staphylococcal Cassette Chromosome mec and ccr Typing}

One hundred and eighty seven MRSA isolates were shown to carry SCCmec type III and were PCR-positive with the $c c r A B-\alpha 4$ specific primers indicating the presence of type $3 \mathrm{ccr}$. Moreover, 13 isolates that showed low resistance to oxacillin ( $\mathrm{MIC}=4 \mu \mathrm{g} / \mathrm{mL}$ ) carried SCCmec type IV and also showed type $2 \mathrm{ccr}$. Moreover, all the seven clinical isolates shared SCCmec type IVa. However, one sewage MRSA isolate (6.7\%) shared SCCmec type IVc.

\subsection{Detection of pvl Gene}

The results of the $p v l$ gene detection among the MRSA isolates showed that only 13 (6.5\%) MRSA isolates were PCR-positive with the $p v l$ gene. These MRSA isolates showed susceptibility to all the antibiotics tested except for penicillin, as expected for MRSA isolates. The presence of $p v l$ gene among the MRSA isolates was limited to isolates that shared type $2 \mathrm{ccr}$ and also showed a low level of oxacillin resistance $(\mathrm{MIC}=4 \mu \mathrm{g} / \mathrm{mL})$.

\section{Discussion}

The frequency of the MRSA strains isolated from a referral hospital in this study was 100 out of 489 (20.4\%), which was less than other reports from Iran (26-29). The differences observed could be due to the methods and techniques used, geographical locations, population, antibiotics prescription, and hygiene measures in different hospitals. Our study showed the presence of a high number and diverse PhP types of MRSA in sewage for the first time in Iran (Figure 2). This revealed that different lineages survive in this environment. These findings were not in agreement with other reports indicating the absence or the low prevalence or no survival of $S$. aureus in sewage $(3,12,30,31)$. The modified protocol for isolation of enterococci from sewage, used for isolation of $S$. aureus in this study, could be a possible explanation (13-15). Due to the high clinical prevalence of MRSA in $\operatorname{Iran}(1,17,18,21$, 26-29), its high prevalence in sewage could be expected. Therefore, this may indicate the role of sewage as a potential reservoir for MRSA.

Considering the high isolation of the PhP types from clinical sources, the origin of MRSA in sewage could be the resident population in the area studied (Figure 2). The presence of SCCmec type III, type $3 \mathrm{ccr}$ and also resistance to different classes of antibiotics other than beta-lactam antibiotics indicated a genetic diversity among the isolated MRSA, which was somehow similar to the clinical isolates. This may indicate their hospital origin. On the other hand, the better adaptation of some PhP types (CT2 and CT11) to the sewage environment may indicate that some strains are resident in STP. While in the USA and Europe most of the MRSA strains have only been isolated from patients, there are also some reports of MRSA isolated from sewage in Sweden, Australia and the USA (3, 11, 32,
33). Our results were similar to the reports from Europe, Australia and the USA.

Extensive diversity was detected among the isolates by $\mathrm{PhP}$ analysis. Compared to clinical isolates, more homogeneity was observed among the sewage isolates. Due to high outbreaks of MRSA in Tehran and dissemination of dominant bacterial clones, a consistency was observed among the MRSA PhP types. The acquisition of oxacillin resistance genes by the majority of isolates from different sources may indicate the possibility of horizontal gene transfer. The recovery of PhP types 2 and 11 in different sources and also in different samplings supports the spread of these clonal types in Tehran and also indicates the genetic stability of PhP types in sewage and the clinic. The isolates in the same CT (ie, CT2 and CT11) had the same SCCmec type, which was similar to other report from Iran (29).

Similar to other studies in Iran $(26,27,29)$, our findings showed that SCCmec type III was the dominant type in clinical and sewage MRSA isolates, which was followed by SCCmec type IV.All the MRSA isolates (clinical and sewage) that shared SCCmec type IV (a or c), showed susceptibility to all the classes of antibiotics tested except for penicillin. It was contrary to other reports suggesting that strains harboring SCCmec type IV can acquire resistance to other classes of antibiotics to survive in the hospital environment. This might in part be due to their new distribution from the community to hospital. The high prevalence of SCCmec type III and also type $3 \mathrm{ccr}$ as indicators of HAMRSA in sewage strains suggests the clinical origin of these isolates. The frequency of CA-MRSA in this study was higher than the report by Fatholahzadeh et al. (26), but is in agreement with our previous report (29). These findings revealed that frequency of CA-MRSA is increasing in Tehran. PVL is known as the indicator of CA-MRSA isolates, which was detected in all the MRSA strains that shared SCCmec type IV. These findings were similar to another report from Iran (29). The presence of PVL virulence factor, which is related to severe necrotizing pneumonia and necrotic skin infections, highlighted the important role of CA-MRSA isolates as serious health-threatening agents.

In conclusion, for the first time, we illustrated the presence and persistence of highly-resistant clonal groups of MRSA in sewage and in a clinic in Tehran, Iran, indicating the epidemiological link between the isolates from sewage and human infections. The spread of MRSA isolates via sewage to surface water could be a serious warning for public health, which emphasizes the importance of sewage treatment process.

\section{Acknowledgements}

Authors would like to thank Dr. Ali Jaralahi for providing the clinical strains.

\section{Authors' Contributions}

Majid Bouzari supervised, developed the study concept, 
and design and critical revision of the manuscript; Fateh Rahimi researched and contributed to the development of drafting and critical revision of the manuscript.

\section{Funding/Support}

This research was funded by an operating grant from the Dean of Research and Graduate Studies at University of Isfahan.

\section{References}

1. Javidnia S, Talebi M, Saifi M, Katouli M, Rastegar Lari A, Pourshafie MR. Clonal dissemination of methicillin-resistant Staphylococcus aureus in patients and the hospital environment. Int J Infect Dis. 2013;17(9):e691-5.

2. Lindsay JA, Holden MT. Staphylococcus aureus: superbug, super genome? Trends Microbiol. 2004;12(8):378-85.

3. Borjesson S, Matussek A, Melin S, Lofgren S, Lindgren PE. Methicillin-resistant Staphylococcus aureus (MRSA) in municipal wastewater: an uncharted threat? J Appl Microbiol. 2010;108(4):1244-51.

4. Hanssen AM, Ericson Sollid JU. SCCmec in staphylococci: genes on the move. FEMS Immunol Med Microbiol. 2006;46(1):8-20.

5. Monecke S, Gavier-Widen D, Mattsson R, Rangstrup-Christensen L, Lazaris A, Coleman DC, et al. Detection of mecC-positive Staphylococcus aureus (CC130-MRSA-XI) in diseased European hedgehogs (Erinaceus europaeus) in Sweden. PLoS One. 2013;8(6):e66166.

6. Kluytmans-Vandenbergh MF, Kluytmans JA. Community-acquired methicillin-resistant Staphylococcus aureus: current perspectives. Clin Microbiol Infect. 2006;12 Suppl 1:9-15.

7. Watkinson AJ, Murby EJ, Kolpin DW, Costanzo SD. The occurrence of antibiotics in an urban watershed: from wastewater to drinking water. Sci Total Environ. 2009;407(8):2711-23.

8. Allen HK, Donato J, Wang HH, Cloud-Hansen KA, Davies J, Handelsman J. Call of the wild: antibiotic resistance genes in natural environments. Nat Rev Microbiol. 2010;8(4):251-9.

9. Ohlsen K, Ternes T, Werner G, Wallner U, Loffler D, Ziebuhr W, et al. Impact of antibiotics on conjugational resistance gene transfer in Staphylococcus aureus in sewage. Environ Microbiol. 2003;5(8):711-6.

10. Borjesson S, Dienues O, Jarnheimer PA, Olsen B, Matussek A, Lindgren PE. Quantification of genes encoding resistance to aminoglycosides, beta-lactams and tetracyclines in wastewater environments by real-time PCR. Int J Environ Health Res. 2009;19(3):219-30.

11. Borjesson S, Melin S, Matussek A, Lindgren PE. A seasonal study of the mecA gene and Staphylococcus aureus including methicillin-resistant $S$. aureus in a municipal wastewater treatment plant. Water Res. 2009;43(4):925-32.

12. Volkmann H, Schwartz T, Bischoff P, Kirchen S, Obst U. Detection of clinically relevant antibiotic-resistance genes in municipal wastewater using real-time PCR (TaqMan). J Microbiol Methods. 2004;56(2):277-86.

13. Rahimi F, Talebi M, Saifi M, Pourshafie MR. Distribution of enterococcal species and detection of vancomycin resistance genes by multiplex PCR in Tehran sewage. Iran Biomed J. 2007;11(3):161-7.

14. Talebi M, Rahimi F, Katouli M, Kühn I, Möllby R, Eshraghi S, et al. Prevalence and Antimicrobial Resistance of Enterococcal Species in Sewage Treatment Plants in Iran. Water, Air, and Soil Pollution. 2007;185(1-4):111-9.

15. Talebi M, Rahimi F, Katouli M, Mollby R, Pourshafie MR. Epidemiological link between wastewater and human vancomycin-resistant Enterococcus faecium isolates. Curr Microbiol. 2008;56(5):468-73.

16. Kateete DP, Kimani CN, Katabazi FA, Okeng A, Okee MS, Nanteza A, et al. Identification of Staphylococcus aureus: DNase and Man- nitol salt agar improve the efficiency of the tube coagulase test. Ann Clin Microbiol Antimicrob. 2010;9:23.

17. Rahimi F, Bouzari M, Katouli M, Pourshafie M. Prophage Typing of Methicillin Resistant Staphylococcus aureus Isolated from a Tertiary Care Hospital in Tehran, Iran. Jundishapur J Microbiol. 2012;6(1):80-5.

18. Rahimi F, Bouzari M, Katouli M, Pourshafie MR. Antibiotic Resistance Pattern of Methicillin Resistant and Methicillin Sensitive Staphylococcus aureus Isolates in Tehran, Iran. Jundishapur J Microbiol. 2013;6(2).

19. Clinical and Laboratory Standard Institute. Performance standards for antimicrobial susceptibility testing, 16th informational supplement. Wayne: Clinical and Laboratory Standard Institute; 2006.

20. Du Z, Yang R, Guo Z, Song Y, Wang J. Identification of Staphylococcus aureus and determination of its methicillin resistance by matrix-assisted laser desorption/ionization time-of-flight mass spectrometry. Anal Chem. 2002;74(21):5487-91.

21. Rahimi F, Bouzari M, Katouli M, Pourshafie MR. Prophage and antibiotic resistance profiles of methicillin-resistant Staphylococcus aureus strains in Iran. Arch Virol. 2012;157(9):1807-11.

22. Zhang K, McClure JA, Elsayed S, Louie T, Conly JM. Novel multiplex PCR assay for characterization and concomitant subtyping of staphylococcal cassette chromosome mec types I to $\mathrm{V}$ in methicillin-resistant Staphylococcus aureus. J Clin Microbiol. 2005;43(10):5026-33.

23. McClure JA, Conly JM, Lau V, Elsayed S, Louie T, Hutchins W, et al. Novel multiplex PCR assay for detection of the staphylococcal virulence marker Panton-Valentine leukocidin genes and simultaneous discrimination of methicillin-susceptible from -resistant staphylococci. J Clin Microbiol. 2006;44(3):1141-4.

24. Persson L, Strid H, Tidefelt U, Soderquist B. Phenotypic and genotypic characterization of coagulase-negative staphylococci isolated in blood cultures from patients with haematological malignancies. Eur J Clin Microbiol Infect Dis. 2006;25(5):299-309.

25. Sneath P. H., Sokal RR. Numerical taxonomy. Taylor \& Francis, Ltd; 1973.

26. Fatholahzadeh B, Emaneini M, Gilbert G, Udo E, Aligholi M, Modarressi MH, et al. Staphylococcal cassette chromosome mec (SCCmec) analysis and antimicrobial susceptibility patterns of methicillin-resistant Staphylococcus aureus (MRSA) isolates in Tehran, Iran. Microb Drug Resist. 2008;14(3):217-20.

27. Japoni A, Jamalidoust M, Farshad S, Ziyaeyan M, Alborzi A, Japoni $\mathrm{S}$, et al. Characterization of SCCmec types and antibacterial susceptibility patterns of methicillin-resistant Staphylococcus aureus in Southern Iran. Jpn J Infect Dis. 2011;64(1):28-33.

28. Rahimi F, Bouzari M, Maleki Z, Rahimi F. Antibiotic susceptibility pattern among Staphylococcus spp. with emphasis on detection of mecA gene in methicillin resistant Staphylococcus aureus isolates. Clin Infect Dis. 2009;4(3):143-50.

29. Rahimi F, Katouli M, Pourshafie MR. Characteristics of hospitaland community-acquired meticillin-resistant Staphylococcus aureus in Tehran, Iran.J Med Microbiol. 2014;63(Pt 6):796-804.

30. Savichtcheva O, Okayama N, Okabe S. Relationships between Bacteroides 16S rRNA genetic markers and presence of bacterial enteric pathogens and conventional fecal indicators. Water Res. 2007;41(16):3615-28.

31. Schwartz T, Kohnen W, Jansen B, Obst U. Detection of antibioticresistant bacteria and their resistance genes in wastewater, surface water, and drinking water biofilms. FEMS Microbiol Ecol. 2003;43(3):325-35.

32. Rosenberg Goldstein RE, Micallef SA, Gibbs SG, Davis JA, He X, George A, et al. Methicillin-resistant Staphylococcus aureus (MRSA) detected at four U.S. wastewater treatment plants. Environ Health Perspect. 2012;120(11):1551-8.

33. Thompson JM, Gundogdu A, Stratton HM, Katouli M. Antibiotic resistant Staphylococcus aureus in hospital wastewaters and sewage treatment plants with special reference to methicillin-resistant Staphylococcus aureus (MRSA). J Appl Microbiol. 2013;114(1):44-54 